\title{
Expression and phosphorylation of FOXO1 influences cell proliferation and apoptosis in the gastrointestinal stromal tumor cell line GIST-T1
}

\author{
TAO WANG ${ }^{1,2}$, HUI ZHAO ${ }^{3 *}$, HUA GAO $^{1,2}$, CHANGMING ZHU $^{1,2}$, \\ YAO XU ${ }^{1,2}$, LIPING BAI ${ }^{1,2}$, JUNBO LIU ${ }^{1,2}$ and FENG YAN ${ }^{1,2}$ \\ ${ }^{1}$ Department of Gastrointestinal Surgery, The Affiliated Zhongshan Hospital of Xiamen University; \\ ${ }^{2}$ Institute of Gastrointestinal Oncology, Medical College of Xiamen University, Xiamen, Fujian 361004; \\ ${ }^{3}$ Medical Cosmetology, Xiamen Hospital of Traditional Chinese Medicine, Xiamen, Fujian 361009, P.R. China
}

Received December 16, 2016; Accepted July 27, 2017

DOI: $10.3892 /$ etm.2018.5853

\begin{abstract}
The mitogen-activated protein kinase (MAPK) and phosphatidylinositol 3-kinase (PI3K) pathways are activated during pathogenesis of gastrointestinal stromal tumors (GISTs). Forkhead box protein O1 (FOXO1) is a transcription factor regulated by the MAPK and PI3K pathways and is associated with multiple metabolic reactions. The present study aims to investigate the association of FOXO1 with cell proliferation and apoptosis in the cell line, GIST-T1. Cell counting kit- 8 assay revealed that cell growth was inhibited by the PI3K inhibitor, LY294002, and/or MAPK inhibitor, UO126. Western blotting demonstrated that the expression of p-FOXO1 and B-cell lymphoma $2(\mathrm{Bcl} 2)$ were significantly reduced, whereas the expression of Bcl-2-associated $\mathrm{X}$ protein was significantly increased following treatment with LY294002 and/or UO126 (all P<0.05). However, no significant change was revealed in the level of total FOXO1. Flow cytometry revealed that apoptosis was significantly increased by the pathway inhibitors $(\mathrm{P}<0.05)$. Specifically, the proportion of cells in the G1 phase was increased whereas the proportion in the $\mathrm{S}$ phase was reduced. The changes of protein expression and cell apoptosis were more evident in the LY294002 + UO126 group than in either single-inhibitor group. The results indicated that FOXO1 was able to affect cell proliferation, apoptosis and the cell cycle of GISTs. The regulation of FOXO1 was part of the PI3K and MAPK
\end{abstract}

Correspondence to: Dr Feng Yan, Department of Gastrointestinal Surgery, The Affiliated Zhongshan Hospital of Xiamen University, 201-209 Hubin South Road, Xiamen, Fujian 361004, P.R. China E-mail: yanfengxmzsh@hotmail.com

${ }^{*}$ Contributed equally

Key words: gastrointestinal stromal tumor, forkhead box protein $\mathrm{O}$, proliferation, apoptosis, phosphorylation signaling network, while this regulation was mostly activated by phosphorylation of FOXO1.

\section{Introduction}

Gastrointestinal stromal tumors (GISTs) were initially classified by Mazur and Clark in 1983 (1), and represent a wide spectrum of mesenchymal tumors in the entire gastrointestinal tract (2). GISTs are most commonly observed in the stomach and small intestine, followed by the colon, rectum and esophagus. They typically occur in individuals $>50$ years old and the incidence of GISTs is 10-20 individuals in a million (3). A notable feature of GISTs is that mutations within the KIT or platelet-derived growth factor receptor (PDGFR) genes exist in the majority of cancer cells (4). Normally, c-KIT activation requires binding to its ligand, stem cell factor (SCF). Interaction between c-KIT and SCF activates a cascade of downstream reactions, whereas mutations in the KIT gene lead to uncontrolled activation of the tyrosine kinase domain and promoted cell proliferation (5). Activation of KIT is crucial for the pathogenesis of the majority of GISTs (6), which makes this oncoprotein a potential therapeutic target. Furthermore, imatinib and other tyrosine kinase inhibitors are typically used to treat GISTs (7).

The downstream signaling pathways that are known to be activated by KIT include the RAS/mitogen-activated protein kinase (MAPK) and phosphatidylinositol 3-kinase $(\mathrm{PI} 3 \mathrm{~K}) /$ protein kinase B networks $(8,9)$. Forkhead box protein $\mathrm{O} 1$ (FOXO1) is a member of the FOXO transcription factors, which has been demonstrated to be closely associated with cell apoptosis, DNA damage or repair, cell autophagy, oxidative stress, angiogenesis and sugar metabolism (10-12). Furthermore, the PI3K and MAPK networks are key signaling pathways that regulate FOXO1 expression (13). A previous study demonstrated that high expression of FOXO1 is able to inhibit cell proliferation (14). However, the potential association of FOXO1 expression in GISTs remains unclear. The present study was designed to investigate the regulatory mechanism by which the PI3K and MAPK signaling pathways influence the activity of FOXO1 and its downstream factors, B-cell lymphoma $2(\mathrm{Bcl} 2)$ and $\mathrm{Bcl}-2$-associated $\mathrm{X}$ protein (Bax). 


\section{Materials and methods}

Reagents. The PI3K inhibitor, LY294002 hydrochloride (cat. no. L9908) and the MAPK inhibitor, UO126 monoethanolate (cat. no. U126) were purchased from Sigma-Aldrich (Merck KGaA, Darmstadt, Germany). Rabbit monoclonal antibody to c-Kit was purchased from Abcam (cat. no. ab32363; Cambridge, MA, USA). Rabbit monoclonal antibodies to FOXO1 (cat. no. 2880S), phosphorylated (p)-FOXO1 (s256, cat. no. 84192S), Bcl2 (cat. no. 4223S) and Bax (cat. no. 5023S) were purchased from Cell Signaling Technology, Inc. (Danvers, MA, USA). Mouse anti- $\beta$-actin (cat. no. sc-47778), horseradish peroxidase (HRP)-conjugated goat anti-rabbit immunoglobulin G (IgG; cat. no. sc-2030) and HRP-conjugated goat anti-mouse IgG (cat. no. sc-2055) were purchased from Santa Cruz Biotechnology, Inc. (Dallas, TX, USA). Tetramethylrhodamine-conjugated donkey anti-human IgG (cat. no. D110143) and cell counting kit-8 (CCK-8 kit; cat. no. E606335) were purchased from Sangon Biotech Co., Ltd. (Shanghai, China). The MaxVision immunohistochemistry kit (cat. no. KIT-5002) was purchased from Fuzhou Maixin Biotech Co., Ltd. (Fuzhou, China). DAPI (cat. no. 10236276001) was purchased from Roche Diagnostics (Basel, Switzerland). The GIST-T1 gastrointestinal stromal tumor cell line was purchased from Biowit Technologies, Ltd. (Shenzhen, China) and the WI-38 normal lung fibroblast cell line was obtained from Shanghai Institute of Biochemistry and Cell Biology (Shanghai, China). The media used for cell culture [Dulbecco's modified Eagle's medium (DMEM), minimum essential media (MEM) and fetal calf serum] were purchased from Gibco (Thermo Fisher Scientific, Inc., Waltham, MA, USA).

Cell culture and treatments. GIST-T1 cells, characterized in detail by Taguchi et al (15), were cultured in DMEM and WI-38 cells (ATCC ${ }^{\circledR}$ CCL-75 ${ }^{\text {TM }}$ ) in MEM. Both media were supplemented with $10 \%$ fetal calf serum and maintained at $37^{\circ} \mathrm{C}$ in a humidified atmosphere containing $5 \% \mathrm{CO}_{2}$ and $95 \%$ air. The GIST-T1 cells were maintained in the log-growth phase and treatment groups were treated with $30 \mu \mathrm{M}$ LY294002 (LY294002 group), $10 \mu \mathrm{M}$ UO126 (UO126 group) or $30 \mu \mathrm{M}$ $\mathrm{LY} 294002+10 \mu \mathrm{M}$ UO126 (LY+UO group) at $37^{\circ} \mathrm{C}$ for $24 \mathrm{~h}$. An equal amount of dimethylsulfoxide (DMSO) was added into the control group and incubated at $37^{\circ} \mathrm{C}$ for $24 \mathrm{~h}$.

Immunocytochemistry and immunofluorescence staining. GIST-T1 cells were seeded into six-well chamber slides at a density of $1 \times 10^{4}$ cells/well and allowed to adhere. Subsequently, $1 \mathrm{ml}$ medium was added to each well and cultures were maintained at $37^{\circ} \mathrm{C}$ for $24 \mathrm{~h}$, then washed and fixed with acetone at $4^{\circ} \mathrm{C}$ for $20 \mathrm{~min}$. Cells were permeabilized with $0.5 \%$ Triton X-100 for $20 \mathrm{~min}$. To inhibit endogenous peroxidase activity, slides were incubated at $37^{\circ} \mathrm{C}$ with $3 \% \mathrm{H}_{2} \mathrm{O}_{2}$ for 10 min, washed with PBS and blocked with $5 \%$ bovine serum albumin (Biosharp, Anhui, China) at room temperature for $30 \mathrm{~min}$. Excess serum was removed with filter paper, and the primary c-Kit antibody (1:500) was added and incubated at $4^{\circ} \mathrm{C}$ overnight. Following washing three times with PBS for 5 min each, the HRP-labeled Goat Anti-Mouse IgG (1:50) or DyLight 405-labeled Goat Anti-Mouse IgG (1:200) was added and incubated at room temperature for $30 \mathrm{~min}$ and washed three times with PBS for 5 min each. For peroxidase staining, color was developed using 3,3'-diaminobenzidine, slides were washed to terminate the reaction and then nuclei were counterstained with hematoxylin at room temperature for $30 \mathrm{sec}$. For immunofluorescence staining, nuclei were counterstained with DAPI at room temperature for $15 \mathrm{~min}$, slides were dried and then sealed with neutral resin. Slides were observed under a light or a fluorescence microscope (magnification, x400) and images were captured.

CCK-8 cell proliferation assay. A single-cell suspension of GIST-T1 was seeded into 96 -well plates at $1 \times 10^{5}$ cells per well and treated with inhibitors as described above. Following treatment for $0,12,24,36$ or $48 \mathrm{~h}, 10 \mu \mathrm{l} \mathrm{CCK}-8$ reagent was added, samples were incubated at $37^{\circ} \mathrm{C}$ and $5 \% \mathrm{CO}_{2}$ for $1 \mathrm{~h}$ and agitated gently to ensure any precipitate was dissolved. The absorbance of each well was measured with a microplate reader, at an absorption wavelength of $450 \mathrm{~nm}$. With the measured optical densities (ODs), the following formula was used: Inhibition ratio $(\%)=(\mathrm{OD}$ value of control group $-\mathrm{OD}$ value of experimental group)/OD value of control group x 100 .

Western blotting. Cell cultures were treated as described above. At the end of the culture period, the total protein was extracted from the cells in $100 \mu 1$ extraction buffer $(10 \mathrm{mM}$ Tris, $1 \mathrm{mM}$ EDTA, $1 \%$ SDS, $0.1 \%$ Triton X-100 containing complete protease inhibitor cocktail). A bicinchoninic acid protein assay kit (Pierce; Thermo Fisher Scientific, Inc.) was used to estimate the protein content of the lysate with bovine serum albumin used as the standard. SDS loading buffer [63 mM Tris- $\mathrm{HCl}, 10 \%$ glycerol, $2 \%$ SDS, $0.0025 \%$ bromophenol blue, (pH 6.8)] was added following normalization of the concentration of protein in each sample with $1 \%$ SDS. Protein lysates $(30 \mu \mathrm{g})$ were separated by $8 \%$ SDS-PAGE and electrophoretically transferred onto PVDF membranes (EMD Millipore, Billerica, MA, USA). Membranes were blocked with $5 \%$ non-fat dry milk (w/v) in TBST buffer $(10 \mathrm{mM}$ Tris, $150 \mathrm{mM} \mathrm{NaCl}, 0.05 \%$ Tween-20) at room temperature for $1 \mathrm{~h}$, and incubated overnight with primary antibodies against FOXO1 (1:1,000), p-FOXO1 (s256; 1:1,000), Bcl2 (1:1,000), Bax $(1: 1,000)$ or $\beta$-actin $(1: 2,000)$ at $4^{\circ} \mathrm{C}$. Subsequently, blots were washed three times with TBST and incubated with HRP-conjugated secondary antibody against IgG $(1: 3,000)$ at room temperature for $1 \mathrm{~h}$. Enhanced chemiluminescence substrate followed by exposure within an EpiChemi II darkroom (UVP, Inc., Upland, CA, USA) was used for visualization of the protein bands. Quantity One software v4.62 (Bio-Rad Laboratories, Inc., Hercules, CA, USA) was used to analyze the bands and quantify the signal.

Apoptosis assay by flow cytometry. Cultured GIST-T1 cells were treated and collected as described above. Apoptosis was analyzed to investigate whether LY294002 and UO126 were able to enhance cell killing sensitivity. The apoptotic rates were measured using a flow cytometric assay. Cell labeling was performed using Annexin $\mathrm{V}$ conjugated to fluorescein isothiocyanate (FITC), which binds to phosphatidylserine exposed on the surface membrane of cells undergoing apoptosis. Cells were collected by trypsinization, washed twice with PBS and centrifuged at $500 \mathrm{xg}$, room temperature for $5 \mathrm{~min}$. The cells 

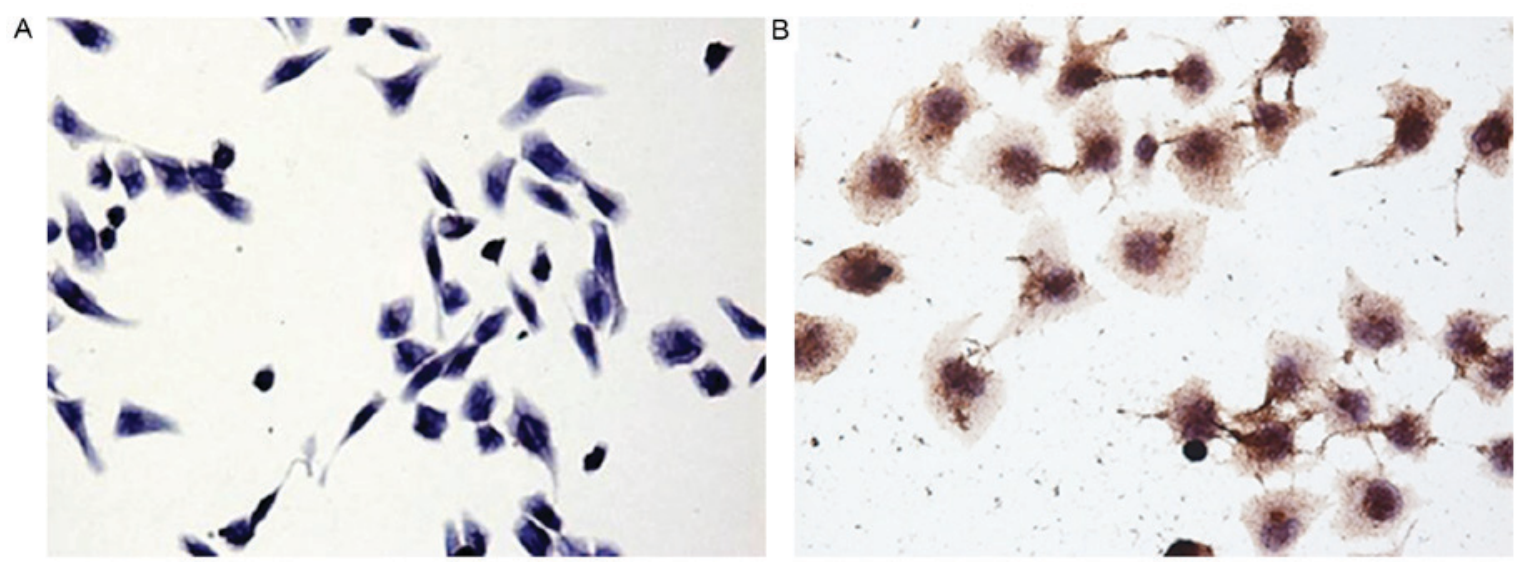

Figure 1. Immunocytochemical staining of cultured GIST-T1 cells. (A) Gastrointestinal stromal tumor cell marker c-Kit was negative in the control group (with PBS replacing the c-kit antibody). (B) Positive staining for the gastrointestinal stromal tumor cell marker c-Kit was observed in the experimental group. Magnification, x400.

were then suspended in $500 \mu \mathrm{l}$ PBS and incubated with $5 \mu \mathrm{l}$ Annexin V-FITC (Annexin V-FITC Apoptosis Detection Kit; Beyotime Institute of Biotechnology, Haimen, China) and $10 \mu \mathrm{l}$ (20 $\mu \mathrm{g} / \mathrm{ml}$ ) propidium iodide (PI) solution (Beyotime Institute of Biotechnology) at room temperature for $20 \mathrm{~min}$ in the dark. The samples were then measured using a flow cytometer with FACS 101 software (BD Biosciences, Franklin Lakes, NJ, USA). For each sample, $10^{5}$ fluorescence signals were measured.

Cell cycle distribution assay by flow cytometry. GIST-T1 cells were treated and collected as described above, then fixed in $75 \%$ ethanol for $2 \mathrm{~h}$ at $4^{\circ} \mathrm{C}$. Samples were rehydrated with PBS and incubated with $500 \mu \mathrm{l}(200 \mu \mathrm{g} / \mathrm{ml})$ PI solution for $30 \mathrm{~min}$ at room temperature. For each sample the percentages of cells in the G0/G1, S and G2/M phases of the cell cycle were calculated using a flow cytometer with FACS software. For each sample, 10,000 fluorescence signals were measured.

Statistical methods for data analysis. SPSS 20.0 software (IBM Corp., Armonk, NY, USA) was used for statistical analysis of experimental data. The results are expressed as the mean \pm standard deviation. $\mathrm{P}<0.05$ was considered to indicate a statistically significant difference. Differences between groups were determined by one-way analysis of variance with Dunnett's post hoc test.

\section{Results}

Confirmation of cell type by immunocytochemistry. Immunocytochemical staining of cultured GIST-T1 cells with an anti-c-Kit antibody revealed brown granules in the cytoplasm (Fig. 1). The presence of this gastrointestinal stromal tumor cell marker indicated that the cells cultured in the present study were from a gastrointestinal stromal tumor.

Cell proliferation is inhibited by signaling inhibitors. CCK-8 staining revealed that the inhibition of cell proliferation was enhanced with treatment time in the LY+UO group $(\mathrm{P}<0.05$; Fig. 2). Inhibition of cell proliferation inhibition in the LY+UO group was more pronounced compared with groups treated with either inhibitor alone $(\mathrm{P}<0.05$; Fig. 2). Furthermore,

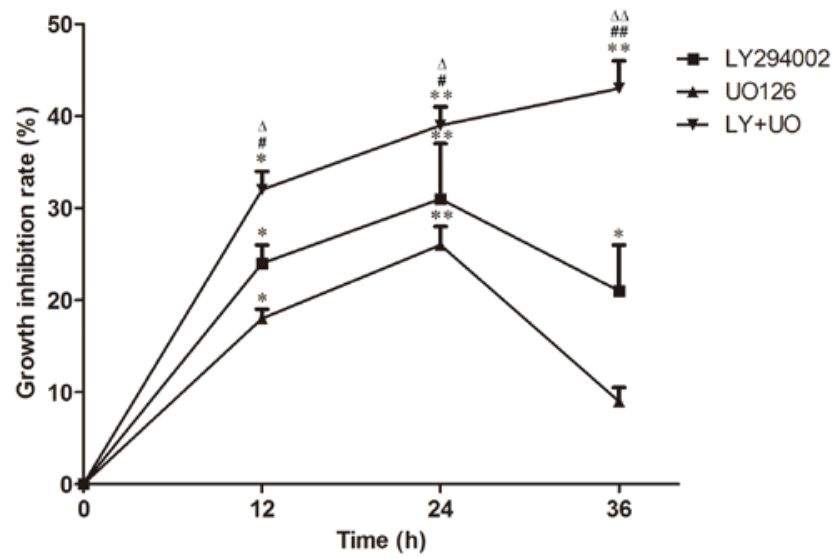

Figure 2. Cell Counting Kit-8 assay was used to evaluate the growth inhibition of GIST-T1 cells treated with phosphoinositide 3-kinase inhibitor LY294002, mitogen-activated protein kinase inhibitor UO126, and a combination of LY294002 + UO126. Error bars indicate the standard deviations. ${ }^{*} \mathrm{P}<0.05$ and ${ }^{* *} \mathrm{P}<0.01$ vs. $0 \mathrm{~h} ;{ }^{\#} \mathrm{P}<0.05$ and ${ }^{\# \#} \mathrm{P}<0.01$ vs. LY294002; ${ }^{\Delta} \mathrm{P}<0.05$ and ${ }^{\Delta \Delta} \mathrm{P}<0.01$ vs. UO126. LY+UO, LY294002 + UO126.

maximal inhibition was observed when cultures were treated with LY294002 or UO126 for $24 \mathrm{~h}$, whereas inhibition peaked at $36 \mathrm{~h}$ in the LY+UO group, at which time-point the majority of cells were dead (Fig. 2).

Western blotting analysis. Western blotting revealed that the expression of FOXO1 and Bax significantly decreased, whereas p-FOXO1 and Bcl2 significantly increased in GIST-T1 cells compared with the normal human fibroblasts WI-38 $(\mathrm{P}<0.05$; Fig. 3A). To confirm that protein expression was regulated via the PI3K or MAPK pathways, the cells were treated with pathway inhibitors. The protein expression of p-FOXO1 and $\mathrm{Bcl} 2$ was significantly decreased (both $\mathrm{P}<0.05$ ), whereas Bax $(\mathrm{P}<0.05)$ increased in cells treated with LY294002, UO126 or both compared with controls. The reduction in the expression of p-FOXO1 and $\mathrm{Bcl} 2$ and the increase in protein expression of Bax were more marked in the LY+UO group; however, total FOXO1 protein expression was not significantly different among the groups treated with LY294002, UO126, LY+UO or DMSO (Fig. 3B). 
A



Figure 3. (A) Western blotting was used to analyze the protein expression of FOXO1, p-FOXO1, Bcl2 and Bax in GIST-T1 and WI-38 cells (normal human fibroblasts). "P<0.05 vs. WI-38 cells. (B) Western blotting was used to analyze protein expression of FOXO1, p-FOXO1, Bcl2 and Bax in cells treated with LY294002 and UO126 alone or in combination. ${ }^{*} \mathrm{P}<0.05$ vs. DMSO. Error bars indicate the standard deviations. FOXO1, forkhead box protein O1; p, phosphorylated; Bcl2, B-cell lymphoma 2; Bax, Bcl-2-associated X protein; DMSO, dimethylsulfoxide; LY+UO, LY294002 + UO126.

Immunofluorescence staining of FOXO1 distribution. Immunofluorescence staining revealed that FOXO1 was widely distributed in the nucleus and cytoplasm in the DMSO group. Treatment of GIST-T1 cells with LY294002 or UO126 resulted in cytoplasmic levels of FOXO1 being markedly reduced, with a corresponding increase in nuclear FOXO1. Furthermore the degree of FOXO1 translocation to the nucleus in the LY+UO group was more pronounced than in either single-inhibitor group (Fig. 4).

Apoptosis is induced by signaling inhibitors. Cells in the control group exhibited an apoptosis rate of $1.17 \pm 0.21 \%$. In the LY294002-treatment group the apoptosis rate was $2.05 \pm 0.32 \%$ whereas in the UO126-treated group it was $2.66 \pm 0.53 \%$. Additionally, in the LY+UO group the apoptosis rate was $3.82 \pm 0.47 \%$. These results demonstrated a significantly increased apoptosis rate $(\mathrm{P}<0.05)$ when treating GIST-T1 cells with LY294002 or UO126, and the effect of combined treatment was higher than that of either inhibitor alone (Fig. 5).

Signaling inhibitors alter the cell cycle distribution. Flow cytometry revealed that the proportion of G0/G1 phase cells in the LY294002, UO126 and LY+UO groups was 79.78 \pm 5.27 , $73.73 \pm 4.86$ and $87.28 \pm 6.27 \%$, respectively. These proportions were increased significantly compared with the control group at $65.43 \pm 4.35 \%$ (all $\mathrm{P}<0.05)$. The percentages of $\mathrm{S}$ phase cells in three treatment groups were $18.65 \pm 2.17,26.27 \pm 3.14$ and $12.6 \pm 1.73 \%$, respectively. The percentages were also

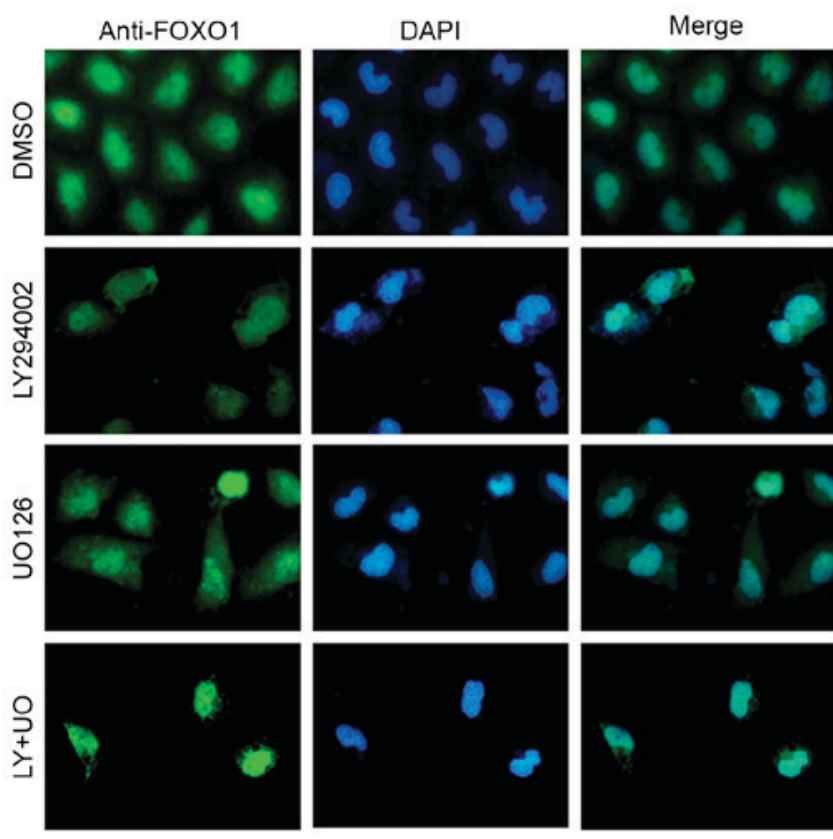

Figure 4. Immunofluorescence to detect the localization of FOXO1 in GIST-T1 cells treated with LY294002 and UO126 alone or in combination. Magnification, $x 400$. FOXO1, forkhead box protein O1; DMSO, dimethylsulfoxide; LY+UO, LY294002 + UO126.

significantly decreased compared with the control group $(32.17 \pm 3.10 \% ; \mathrm{P}<0.05)$. The effect of combination treatment 

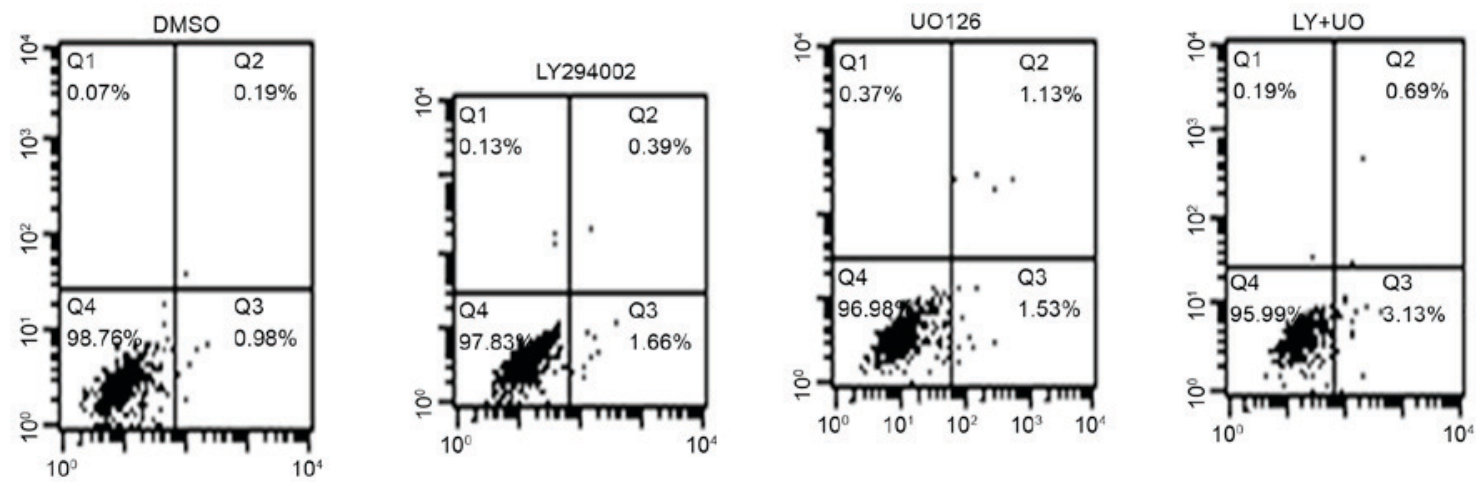

Figure 5. Apoptosis of GIST-T1 cells treated with LY294002 and UO126 alone or in combination. DMSO, dimethylsulfoxide; LY+UO, LY294002 + UO126.
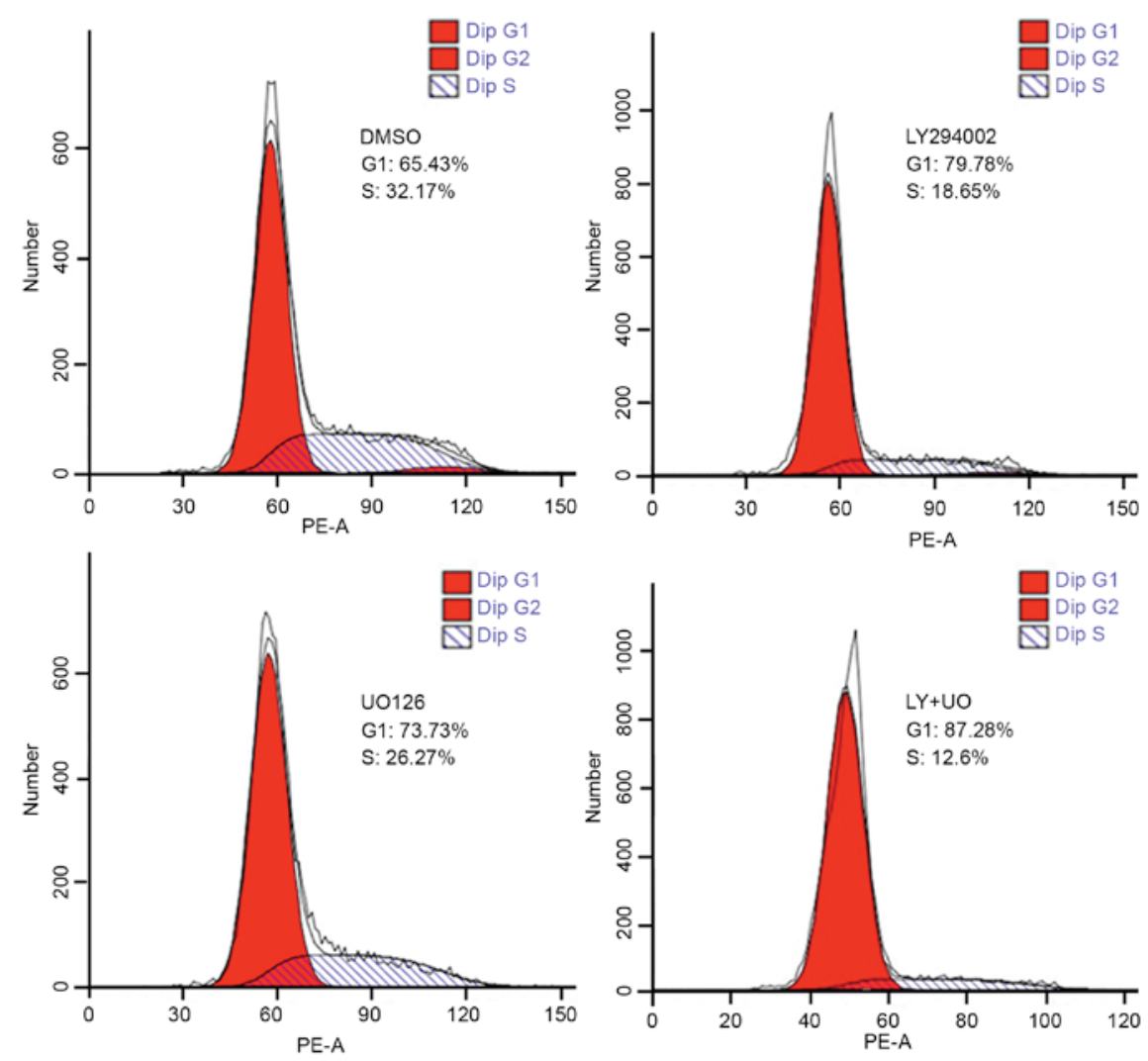

Figure 6. Cell cycle distribution of GIST-T1 cells treated with LY294002 and UO126 alone or in combination. DMSO, dimethylsulfoxide; LY+UO, LY294002 + UO126.

was significantly greater than either inhibitor alone (Fig. 6; all $\mathrm{P}<0.05)$.

\section{Discussion}

The pathogenesis of GISTs is closely associated with uncontrolled cell proliferation and inhibition of apoptosis (16). The PI3K and MAPK pathways serve a vital role in the pathogenesis of GISTs (17). Hyperactivation of the PI3K pathway is associated with constitutive autophosphorylation of c-KIT and cancer growth (9). The present study confirmed that the PI3K and MAPK pathways were associated with cell proliferation and apoptosis, and the cell cycle of GISTs. Furthermore, a previous study indicated that the activation of these pathways may be differential. However, the PI3K pathway appears to be activated to a greater extent than the MAPK pathway in wild-type GIST tissues and PDGFR mutants (17). Additionally, activation of the PI3K pathway, rather than the MAPK pathway, was also associated with drug-resistance to imatinib in GISTs (18). The results of the present study demonstrated that the PI3K inhibitor, LY294002, had a stronger growth inhibition effect than the MAPK inhibitor, UO126. However, the regulatory effect of p-FOXO1, Bcl2 and Bax was more evident by UO126 than by LY249002. The difference between phenotypes and molecular expression indicated that regulation of other molecules may also be responsible.

The PI3K and MAPK signaling pathways are important regulators of FOXO1 (13). FOXO1 is an important transcription factor that is associated with the regulation of cell proliferation and apoptosis. The results revealed, 
that compared with normal fibroblasts, total FOXO1 was suppressed and p-FOXO1 was increased in GIST cells. These results indicated that regulation of FOXO1 was associated with GISTs. Furthermore, a recent study also reported that downregulation of FOXO1 promoted cell proliferation in cervical cancer (11). The activity of FOXO1 may be regulated by phosphorylation, acetylation and other modifications (11). The results of the present study indicated that the PI3K and MAPK pathways regulated FOXO1 by phosphorylation rather than by changing the expression level. Similar results have also been reported previously where studies have demonstrated that the PI3K and MAPK inhibitors were able to inhibit the phosphorylation of FOXO1 and its translocation to the nucleus, and thereby inhibit the transcriptional activity of FOXO1 on downstream factors (19-21).

Previous studies have demonstrated that FOXO1 is associated with the regulation of $\mathrm{Bcl} 2$, $\mathrm{Bax}$ and other apoptosis-related factors $(13,22)$. Furthermore, overexpression of $\mathrm{Bcl} 2$ inhibits apoptosis, whereas overexpression of $\mathrm{Bax}$ is able to promote apoptosis (23). Phosphorylated FOXO1 is able to upregulate $\mathrm{Bcl} 2$ and downregulate Bax expression to inhibit apoptosis $(24,25)$. Consistent with those previous reports, an increased $\mathrm{Bcl} 2$ expression and suppressed $\mathrm{Bax}$ expression along with increased p-FOXO1 was also observed in GIST-T1 cells in the present study. However, treating GIST-T1 cells with LY249002 and UO126 was able to inhibit the activation of FOXO1 into p-FOXO1, and thereby lead to increased apoptosis rate and arrested cell cycle at the G0/G1 phase.

In conclusion, regulation of FOXO1 by the PI3K and MAPK pathways was associated with the pathogenesis of GISTs. The downregulation of total FOXO1 and hyperactivation of p-FOXO1 was associated with cell proliferation, apoptosis rate and altered cell cycle in GIST-T1 cells. Furthermore, the phosphorylation of FOXO1 was activated by the PI3K and MAPK pathways. Therefore, further study of the role of the transcription factor FOXO1 in GISTs is required, as it may provide a novel direction for the development of targeted therapy drugs.

\section{Acknowledgements}

The present study was supported by the Natural Science Foundation of Fujian in China (grant no. 2015J01522).

\section{References}

1. Mazur MT and Clark HB: Gastric stromal tumors: Reappraisal of histogenesis. Am J Surg Pathol 7: 507-519, 1983.

2. Joensuu H, Hohenberger P and Corless CL: Gastrointestinal stromal tumour. Lancet 382: 973-983, 2013.

3. Miettinen $\mathrm{M}$ and Lasota $\mathrm{J}$ : Gastrointestinal stromal tumors. Gastroenterol Clin North Am 42: 399-415, 2013.

4. Duensing A, Heinrich MC, Fletcher CD and Fletcher JA: Biology of gastrointestinal stromal tumors: KIT mutations and beyond Cancer Invest 22: 106-116, 2004.

5. Hirota S, Isozaki K, Moriyama Y, Hashimoto K, Nishida T, Ishiguro S, Kawano K, Hanada M, Kurata A, Takeda M, et al: Gain-of-function mutations of c-kit in human gastrointestinal stromal tumors. Science 279: 577-580, 1998.

6. Sako H, Fukuda K, Saikawa Y, Nakamura R, Takahashi T, Wada N, Kawakubo H, Takeuchi H, Ohmori T and Kitagawa Y: Antitumor effect of the tyrosine kinase inhibitor nilotinib on gastrointestinal stromal tumor (GIST) and imatinib-resistant GIST cells. PLoS One 9: e107613, 2014.
7. Demetri GD, Reichardt P, Kang YK, Blay JY, Rutkowski P, Gelderblom H, Hohenberger P, Leahy M, von Mehren M, Joensuu $\mathrm{H}$, et al: Efficacy and safety of regorafenib for advanced gastrointestinal stromal tumours after failure of imatinib and sunitinib (GRID): An international, multicentre, randomised, placebo-controlled, phase 3 trial. Lancet 381: 295-302, 2013.

8. Rossi F, Ehlers I, Agosti V, Socci ND, Viale A, Sommer G, Yozgat Y, Manova K, Antonescu CR and Besmer P: Oncogenic Kit signaling and therapeutic intervention in a mouse model of gastrointestinal stromal tumor. Proc Natl Acad Sci USA 103: 12843-12848, 2006.

9. Patel S: Exploring novel therapeutic targets in GIST: Focus on the PI3K/Akt/mTOR pathway. Curr Oncol Rep 15: 386-395, 2013.

10. Zhao Y, Yang J, Liao W, Liu X, Zhang H, Wang S, Wang D, Feng J, Yu L and Zhu WG: Cytosolic FoxO1 is essential for the induction of autophagy and tumour suppressor activity. Nat Cell Biol 12: 665-675, 2010.

11. Prasad SB, Yadav SS, Das M, Govardhan HB, Pandey LK, Singh S, Pradhan S and Narayan G: Down regulation of FOXO1 promotes cell proliferation in cervical cancer. J Cancer 5: 655-662, 2014.

12. Matsumoto M, Pocai A, Rossetti L, Depinho RA and Accili D: Impaired regulation of hepatic glucose production in mice lacking the forkhead transcription factor Foxol in liver. Cell Metab 6: 208-216, 2007.

13. Roy SK, Srivastava RK and Shankar S: Inhibition of PI3K/AKT and MAPK/ERK pathways causes activation of FOXO transcription factor, leading to cell cycle arrest and apoptosis in pancreatic cancer. J Mol Signal 5: 10, 2010.

14. Ai J, Duan J, Lv X, Chen M, Yang Q, Sun H, Li Q, Xiao Y, Wang Y, Zhang Z, et al: Overexpression of FoxO1 causes proliferation of cultured pancreatic beta cells exposed to low nutrition. Biochemistry 49: 218-225, 2010.

15. Taguchi T, Sonobe H, Toyonaga S, Yamasaki I, Shuin T, Takano A, Araki K, Akimaru K and Yuri K: Conventional and molecular cytogenetic characterization of a new human cell line, GIST-T1, established from gastrointestinal stromal tumor. Lab Invest 82: 663-665, 2002.

16. Hsu KH, Tsai HW, Lin PW, Hsu YS, Lu PJ and Shan YS: Anti-apoptotic effects of osteopontin through the up-regulation of Mcl-1 in gastrointestinal stromal tumors. World J Surg Oncol 12: $189,2014$.

17. Ríos-Moreno MJ, Jaramillo S, Díaz-Delgado M, Sánchez-León M, Trigo-Sánchez I, Padillo JP, Amérigo J and González-Cámpora R: Differential activation of MAPK and PI3K/AKT/mTOR pathways and IGF1R expression in gastrointestinal stromal tumors. Anticancer Res 31: 3019-3025, 2011.

18. Heinrich MC, Corless CL, Blanke CD, Demetri GD, Joensuu H, Roberts PJ, Eisenberg BL, von Mehren M, Fletcher CD, Sandau K, et al: Molecular correlates of imatinib resistance in gastrointestinal stromal tumors. J Clin Oncol 24: 4764-4774, 2006.

19. Sykes SM, Lane SW, Bullinger L, Kalaitzidis D, Yusuf R, Saez B, Ferraro F, Mercier F, Singh H, Brumme KM, et al: AKT/FOXO signaling enforces reversible differentiation blockade in myeloid leukemias. Cell 146: 697-708, 2011.

20. Asada S, Daitoku H, Matsuzaki H, Saito T, Sudo T, Mukai H, Iwashita S, Kako K, Kishi T, Kasuya Y and Fukamizu A: Mitogen-activated protein kinases, Erk and p38, phosphorylate and regulate Foxo1. Cell Signal 19: 519-527, 2007.

21. Qiang L, Banks AS and Accili D: Uncoupling of acetylation from phosphorylation regulates FoxO1 function independent of its subcellular localization. J Biol Chem 285: 27396-27401, 2010.

22. Moriishi T, Kawai Y, Komori H, Rokutanda S, Eguchi Y, Tsujimoto Y, Asahina I and Komori T: Bcl2 deficiency activates FoxO through Akt inactivation and accelerates osteoblast differentiation. PLoS One 9: e86629, 2014.

23. Teijido O and Dejean L: Upregulation of Bcl2 inhibits apoptosis-driven BAX insertion but favors BAX relocalization in mitochondria. FEBS Lett 584: 3305-3310, 2010.

24. Kim SJ, Winter K, Nian C, Tsuneoka M, Koda Y and McIntosh CH: Glucose-dependent insulinotropic polypeptide (GIP) stimulation of pancreatic beta-cell survival is dependent upon phosphatidylinositol 3-kinase $(\mathrm{PI} 3 \mathrm{~K}) /$ protein kinase $\mathrm{B}$ (PKB) signaling, inactivation of the forkhead transcription factor Foxol, and down-regulation of bax expression. J Biol Chem 280: 22297-22307, 2005.

25. Muranen T, Selfors LM, Worster DT, Iwanicki MP, Song L, Morales FC, Gao S, Mills GB and Brugge JS: Inhibition of $\mathrm{PI} 3 \mathrm{~K} / \mathrm{mTOR}$ leads to adaptive resistance in matrix-attached cancer cells. Cancer Cell 21: 227-239, 2012.

This work is licensed under a Creative Commons Attribution-NonCommercial-NoDerivatives 4.0 International (CC BY-NC-ND 4.0) License. 